\title{
Securitizing Biosecurity: The Scope for Civil-Military Coordination in Pakistan
}

\author{
Dr. Najimdeen Bakare * $\mathcal{E}$ Aisha Ali **
}

\begin{abstract}
Biosecurity is often a downplayed element of human security in Pakistan. The leading cause for this is the existence of multiple definitions that are associated with it. Biosciences and medicine are the only fields perceived to be related to biosecurity; the corresponding sectors to these fields are riddled with poor infrastructure problems and lack of resources. To address the need for biosecurity, Pakistan formulated and ratified policies in accordance with the Biological and Toxins Weapons Convention (BTWC). However, lack of implementation of these policies continually undermines the role that biosecurity plays in the state's entire defense plan. The problem is further compounded by the rising possibility of naturally occurring threats. This study assesses the scope for civil-military coordination to improve Pakistan's current state of biosecurity. It sheds light on the role that generation of information plays in this regard, and how rapidly advancing methods and research in biotechnology increase the threats that may arise from biological agents, mainly through problems of dual-use. This creates a space for coordination amongst the government, military, and academia. However, the two main barriers need to be
\end{abstract}

\footnotetext{
* Dr. Najimdeen Bakare teaches at the Centre for International Peace and Stability (CIPS) NUST, Islamabad

** Aisha Ali, a graduate student at the Centre for International Peace and Stability (CIPS) NUST, Islamabad
}

@2021 by the Islamabad Policy Research Institute.

IPRI Journal $\square \mathrm{XXI}(2): 1-42$

https://doi.org/10.31945/iprij.210201

IPRI JOURNAL $\mathbf{\bullet} 2021$ 
Securitizing Biosecurity: The Scope for Civil-Military Coordination ...

identified: i.e., the differences in the understanding of biosecurity and the distance between the state and the academia. The military is a significant institution in Pakistan, given Pakistan's relations with its neighbours. Hence, a collaborative effort by bio-sciences, Public Health Organizations, the state and the military can help identify and prepare for biological threats.

Keywords: Biosecurity, Securitizing Biosecurity, Civil-Military Coordination (CIMIC), Public-Health, Biosecurity Preparedness 
Securitizing Biosecurity: The Scope for Civil-Military Coordination ...

\section{Introduction}

$\mathrm{T}$ he growing need for focus on biosecurity results from the changing nature of threats that the world faces today; the shifting paradigm from traditional security to human security is one of its signs. Major threats to states are no longer just the states and politics that threaten their borders, it also now includes the disasters that result from climate change, globalization as a whole, and the ever-emerging and/or mutating infectious diseases and viruses that threaten human lives. To adapt to these changes, states need to start taking a more proactive approach to building biosecurity. However, with constant changes in the political landscape and rise in extremism and nationalism, most of the resources of countries such as Pakistan, are dedicated to protecting their borders and maintaining their sovereignty. These countries invest mainly in their militaries and not enough in their public health. As a result, public health delivery mechanisms are slow to respond and inefficient with their resources. Nonetheless, improving public health mechanisms is not the only way to improve biosecurity. Investing more in research and development (R\&D) of affordable drugs and vaccines can help these countries improve their responsiveness and preparedness to any threats of a biological nature. ${ }^{1}$ Additionally, to draw more resources towards health and biosecurity, military interest needs to be augmented in this regard. This paper identifies a major gap in the lack of capacity on the civil and military ends, to improve biosecurity in Pakistan. As a result, the paper establishes the significance of biosecurity and the role that biosciences (as a discipline) can play in it. In the next section, the reader gets an overview of the vast amount of literature on biosecurity vis-à-vis its multifaceted definitions, geared not just to underscore the significance of the subject, but also to help the reader understand the issues and thematic debates of biosecurity. The subsequent section gives an overview of the different security challenges associated with biosecurity. The next session deals

\footnotetext{
${ }^{1}$ Stephen J. Collier, Andrew Lakoff and Paul Rabinow, "Biosecurity: Towards an Anthropology of the Contemporary," Anthropology Today 20, no. 5 (2004): 6. doi:10.1111/j.0268-540x.2004.00292.x.
} 
Securitizing Biosecurity: The Scope for Civil-Military Coordination ...

with an overview of Pakistan's current state, highlighting the major issues that biosecurity faces. The successive section provides a conceptual framework, followed by the methodological considerations, findings and discussions, and the conclusion.

\section{Defining Biosecurity}

According to Gregory Koblentz, "The rise of biosecurity resulted from a growing acceptance of a broader definition of security in the post-Cold War era, and four trends that have increased the risks posed by biological threats to international security: advances in science and technology, the emergence of new diseases, globalization, and the changing nature of conflict." 2 Such a redefinition or rethinking of security posed serious concern for traditionalists in the field of international relations, arguing for a strict definition of security, but which does not include disease as a security threat. ${ }^{3}$

With regards to the definition of biosecurity, scholars agree that it is not a mono-definitional concept, given the varying context and conceptual utility of the word. ${ }^{4}$ They also assert that biosecurity is used interchangeably with biosafety, despite the salient difference in the two concepts. ${ }^{5}$ For Koblentz, the term biosecurity was first introduced and gained importance amongst scholars in the agriculture and environment field. For them, biosecurity describes an approach "designed to prevent or

\footnotetext{
${ }^{2}$ Gregory D. Koblentz, "Biosecurity Reconsidered: Calibrating Biological Threats and Responses," International Security 34, no. 4 (2010): 98.

${ }^{3}$ Stephen M. Walt, "The Renaissance of Security Studies," International Studies Quarterly 35, no. 2 (1991): 229; and Lawrence Freedman, "International Security: Changing Targets," Foreign Policy, no. 110 (1998):48.

${ }^{4}$ Nick Bingham, and Steve Hinchliffe. "Mapping the Multiplicities of Biosecurity," in Biosecurity Interventions: Global Health and Security in Question, ed. Lakoff Andrew and Collier J. Stephen (New York: Columbia University Press, 2008), 180.

${ }^{5}$ Koblentz, "Biosecurity Reconsidered: Calibrating Biological Threats and Responses," 100. And See Simon, Whitby and Malcolm Dando, "Biosecurity Awareness-raising and Education for Life Scientists: What Should Be Done Now?" in Education and Ethics in the Life Sciences: Strengthening the Prohibition of Biological Weapons, ed. Rappert Brian (Canberra: ANU Press, 2010), 181.
} 
Securitizing Biosecurity: The Scope for Civil-Military Coordination ...

decrease the transmission of naturally occurring infectious diseases and pests in the livestock"

Being the international institution for food and agricultural policy, the Food and Agriculture Organization (FAO) has also incorporated biosecurity definition into its scheme of operation, which covers "the introduction of plant pests, animal pests and diseases, and zoonosis, the introduction and release of genetically modified organisms (GMOs) and their products, and the introduction and management of invasive alien species and genotypes" ${ }^{\prime 7}$ In furtherance to this definition, Whitby and Malcolm situate biosecurity within the "threat spectrum ranges from natural disease through to inadvertently caused disease." For them, "biosecurity is the objective of the whole range of policies, such as export controls, biodefence and national implementation of the Convention, that minimize the possibility that the life sciences will be misused for hostile purposes." Christopher Chyba advocated for "surveillance for biosecurity" or "strategy of public health surveillance" that caters for the threat of bioterrorism, ${ }^{9}$ whereas, Christian Enemark argues for biodefense capability to mitigate and "defend a state's population against future biological attacks." 10 The threat of biosecurity points at the need for regulatory bodies - for "the protection of microbial agents from loss, theft, diversion or intentional misuse" 11 and to ensure "techniques and technologies that can be used to create new pathogenic organisms or

${ }^{6}$ Koblentz, "Biosecurity Reconsidered: Calibrating Biological Threats and Responses," 105.

7 Food and Agriculture Organization Committee on Agriculture, "Biosecurity in Food and Agriculture," 17th sess., (Rome, Italy, March 31-April 4, 2003), 1.

8 Simon Whitby and Malcolm Dando, "Biosecurity Awareness-raising and Education for Life Scientists: What should be done now," 183.

9 Lyle Fearnley, "Redesigning syndromic surveillance for biosecurity," in Biosecurity Interventions, 64.

${ }^{10}$ Christian Enemark, "Biodefense and the Security Dilemma," in Biosecurity Dilemmas: Dreaded Diseases, Ethical Responses, and the Health of Nations (Washington, DC: Georgetown University Press, 2017), 36.

${ }^{11}$ Department of Health and Human Services (HHS), Biosafety in Microbiological and Biomedical Laboratories, 5th ed. (U.S. Government Printing Office Washington: 1999), 8. 
Securitizing Biosecurity: The Scope for Civil-Military Coordination ...

biological active compound," 12 and for dual-use research. For an encompassing perspective of biosecurity, the National Academies of Science puts it as "security against the inadvertent, inappropriate, or intentional malicious or malevolent use of potentially dangerous biological agents or biotechnology, including the development, production, stockpiling, or use of biological weapons as well as outbreaks of newly emergent and epidemic disease." 13

In addition to reviewing literature on biosecurity, it is also imperative to understand the need for Civil-Military Coordination (CIMIC) with regards to non-traditional security.

The rise of non-traditional security (NTS) threats, such as "climate change, cross-border environmental degradation and resource depletion, infectious diseases, natural disasters, irregular migration, food shortages, people smuggling, drug trafficking, and other forms of transnational crime," 14 calls for broader security governance and mechanism. Due to the rapidity and unpredictability of NTS, the realization and exigency for Civil-Military Coordination (CIMIC) is increasingly becoming a reality at both national and regional level. ${ }^{15}$ For instance, NTS threats such as the event of September 11, 2001, SARS and other large scale epidemic with greater attendant consequences for human security have necessitated an alignment of the civil and military bureaucracy in the United States. ${ }^{16}$ This

\footnotetext{
${ }^{12}$ Koblentz, "Biosecurity Reconsidered: Calibrating Biological Threats and Responses,"109.

${ }^{13}$ Institute of Medicine and National Research Council. Globalization, Biosecurity, and the Future of the Life Sciences (Washington, DC: National Academies Press, 2006), 32.

${ }^{14}$ Khalid Iqbal, "Contours of Non-Traditional Security Challenges," Criterion 11, no.2 (2016):1-27

${ }^{15}$ Mely Caballero-Anthony, "From Comprehensive Security to Regional Resilience: Coping with Nontraditional Security Challenges," in ASEAN at 50: Building ASEAN Community: Political-Security and Socio-cultural Reflections, ed. Aileen Baviera and Larry Maramis (Jakarta Pusat: ERIA, 2017), 123-145.

${ }^{16} \mathrm{Yu}$ Xiaofeng, "The Emergence of Non-Traditional Security issues in China and Corresponding Strategies," in Transformation of Foreign Affairs and International Relations in China, 1978-2008, ed. Yizhou Wang (Leiden: Brill, 2011), 284.
} 
Securitizing Biosecurity: The Scope for Civil-Military Coordination ...

is true for regional organizations such as the European Union, "developing its own military and civilian capabilities of crisis management, conflict resolution and post-conflict peace building," ${ }^{17}$ and same is true for ASEAN, ${ }^{18}$ and the Asia-Pacific region. ${ }^{19}$ Unlike the traditional threats, which are mostly within the capacity of the military establishment, NTS transcends being the primary responsibility of the military, because of its complexity and as such must be addressed through pragmatic policy measures, involving and enhancing civil-military cooperation. By extension, it will pave the way for "increasing domestic and foreign investments in human capacity-building (social security, healthcare, etc.)." ${ }^{20}$ Augmenting this further, Khalid Iqbal argues that many countries grapple with vulnerable sectors, and many a time, if afflicted by bigger problem, the civilian administration lacks the capacity to confront the challenge(s), which then requires the capacity of other, such as the military, trained and capacitated to handle such threat. ${ }^{21}$ Tsuneo Akaha argues for the preparedness of the society at large, towards "non-traditional security." To him, it deserves similar national attention, often dedicated to traditional security. While there may arise relational difference between the civilian and military sectors, such national attention towards NTS will nonetheless create an alignment of military and the civilian sector, vis-à-vis issue(s) of national interest. ${ }^{22}$ More critically, there are numerous cases of CIMIC with regards to non-

\footnotetext{
${ }^{17}$ Angela Pennisi di Floristella, "Are Non-Traditional Security Challenges Leading Regional Organizations towards Greater Convergence?," Asia Europe Journal 11, (2013): 22.

${ }^{18}$ Mely Caballero-Anthony, "From Comprehensive Security to Regional Resilience: Coping with Non-traditional Security Challenges,"

${ }^{19}$ James M. Keagle, "Non-Traditional Security Threats and Asia-Pacific Regional Cooperation," (2012), https://www.files.ethz.ch/isn/153758/DTP97.pdf

${ }^{20}$ Anca Agachi, "The Miner's Canary: COVID-19 and the Rise of Non-Traditional Security Threats," DefenseOne, May 16, 2020, https://www.defenseone.com/ideas /2020/05/miners-canary-covid-19-and-rise-non-traditional-security-threats/165446/

${ }^{21}$ Khalid Iqbal, "Contours of Non-Traditional Security Challenges,"

${ }^{22}$ Tsuneo Akaha, "Non-traditional Security Cooperation for Regionalism in Northeast Asia," the paper is based on my talk at Waseda University, Tokyo on November 27, 2003, https://core.ac.uk/download/pdf/144457426.pdf
} 
Securitizing Biosecurity: The Scope for Civil-Military Coordination ...

traditional security, at different parts of the world, one of which is in Sri Lanka, where civilian maritime experts, military officials, and lawenforcement agencies have cooperated in devising a plan to curb drug trafficking along the sea routes. Bari refers to this, as an "unorthodox" complex and comprehensive response, paired with effective collaboration. ${ }^{23}$ Hence, in cases where the problem is affecting several aspects of life -- such as society and economy, CIMIC has proven beneficial. In another instance, the Philippines army engaged with NonGovernmental Organizations (NGOs), and the larger communities, in reconstruction, community organization, and disaster response, at the Panay Islands during the Democratic transition, from 2010-2014. ${ }^{24}$ Similarly, a study conducted in Iran, also highlights the need to enhance CIMIC in cases of disaster response. According to this study, Iran's vulnerability to disasters resulting from climate change, requires a comprehensive and holistic approach to disaster management. The authors argue that, although the Iranian Revolutionary Guard does play a key role in the disaster preparedness and response, there is still need for greater coordination amongst the civil workforce and the military to improve preparedness. ${ }^{25}$

\section{Biosecurity and Security Challenges}

The preceding discussion is instructive to an extent of asserting that biosecurity is not only limited to naturally occurring and spontaneous threats but also threats created by man. ${ }^{26}$ It is impossible to be prepared

${ }^{23}$ Bari Abeysekara, "Prospects of Improving Civil-Military Integration to Address Maritime Drug Trafficking in Sri Lanka," 13th International Research Conference General Sir John Kotelawala Defence University (2020) 95.

${ }^{24}$ Rosalie Arcala Hall, "Guardians reinvented: the Philippine army's non-traditional engagements in Panay Island, Philippines," Philippine Political Science Journal 37, no. 2, (2016) 140.

${ }^{25}$ Hassan Araghizadeh, Mahmoudreza Peyravi, Simintaj Sharififar, and Milad Ahmadi Marzaleh, "Civil-Military Coordination (CIMIC) Model in Natural Disasters in Iran," Bulletin of Emergency \& Trauma 8, no. 4 (2020): 218.

${ }^{26}$ Koblentz, "Biosecurity Reconsidered: Calibrating Biological Threats and Responses," 130. 
Securitizing Biosecurity: The Scope for Civil-Military Coordination ...

for every possible threat or risk. ${ }^{27}$ Although no possibility can be ruled out, threats of a biological nature can prove to be, if not more, then at least, equally as dangerous and costly as nuclear attacks. Biosecurity and countering of biological threats deserve attention due to the sheer scope of damage that can occur at an instance of exposure. Biological weapons are found in nature; hence, accessibility to such materials is not an issue. Biosecurity and preparedness are necessary because agents of biological warfare, such as pathogens and toxins, are living beings and can replicate and mutate themselves and affect entire cities and countries. ${ }^{28}$ It is thus imperative to improve response to threats and equally necessary to prevent these threats from transmigrating across territorial borders and improve response mechanisms -- by improving public health.

The inadequacy or lack of preparedness explicate why few biological attacks in the past were unpreventable. ${ }^{29}$ Hence, the imperative for preparedness geared at reducing or even eliminating the repetition of attacks. For instance, the 2001 Anthrax attacks in the US and Aum Shinrikyo's Sarin gas attacks in a Tokyo Subway station. ${ }^{30}$ Preparedness can instrumentally mitigate against the threat of biological attacks by terrorist organizations, who have threatened mass attacks and demonstrated the desire to spread disease amongst the population. However, improving biosecurity via bio-preparedness, requires a multisectoral approach.

The role of biosecurity in conflict, regional stability and cooperation cannot be understated. As the nature of conflict changes over time, becoming more intra-state than inter-state, there have been links between

${ }^{27}$ Stephen J. Collier, Andrew Lakoff and Paul Rabinow, "Biosecurity: Towards an Anthropology of the Contemporary," Anthropology Today 20, no. 5 (2004): 5.

${ }^{28}$ Jonathan B. Tucker, "Preventing the Misuse of Biology: Lessons from the Oversight of Smallpox Virus Research," International Security 31, no. 2 (2006): 125.

${ }^{29}$ Koblentz, "Biosecurity Reconsidered: Calibrating Biological Threats and Responses," 128.

${ }^{30}$ Milton Leitenberg, "Aum Shinrikyo's efforts to produce biological weapons: A case study in the serial propagation of misinformation," Terrorism and Political Violence 11, no. 4 (1999): 150. 
Securitizing Biosecurity: The Scope for Civil-Military Coordination ...

the spread of infectious diseases (such as malaria, HIV/AIDS and other viral respiratory diseases) and internal conflicts. Internal conflicts possibly threaten biosecurity by affecting the public health infrastructure, creating in its wake a large number of Internally Displace Persons (IDPs), who lack access to necessities, such as food, shelter, and sanitation - creating an environment conducive for the spread of disease. ${ }^{31}$ The relationship between regional stability and biosecurity has recently explored the regional responses to viruses like SARS, the Avian Flu (H5N1) and Swine Flu (H1N1). When epidemics like Avian flu and Swine flu spread, the response to these viruses brought to light the shortcomings in the existing bio-preparedness levels. In Southeast Asia, to improve the regional preparedness and response to epidemics, some disease-focused information networks were set up, such as the Mekong Basin Disease Surveillance and the ASEAN +3 EID information center to integrate regional responses to viral outbreaks. Despite creating these information centers and various analytical tools to address the issue, calculating the actual costs of preparedness and ensuring compliance with regional preparedness guidelines for the different states has proven to be challenging. The challenge arises because of the differences in health sectors within the region, and the disparity amongst states regarding access to health care. Additionally, the role that biosecurity plays in conflict, regionalization, and trade is enough to establish its significance as a topic worthy of research, however even then (apart from issues of defining biosecurity) there are problems that may arise when it comes to studying and promoting biosecurity research. The very first problem identified is that many scholars in the field do not agree with the existence of biosecurity or the need for it. The argument presented is that, even in history, there are very few instances where biological agents were weaponized. For instance, the anthrax attacks 2001, Aum Shinrikyo Sarin Gas Attacks. ${ }^{32}$ These instances have been rare because these groups find it

\footnotetext{
${ }^{31}$ Michelle Gayer and Dominique Legros, "Conflict and Emerging Infectious Diseases," Emerging Infectious Diseases 14, no. 6 (2008): 1005, doi:10.3201/eid1406.080027.

${ }^{32}$ Carlo Caduff, "On the verge of Death: Visions of Biological Vulnerability," Annual Review of Anthropology 43, no. 1 (2014): 115, doi:10.1146/annurev-anthro-102313030341 .
} 
Securitizing Biosecurity: The Scope for Civil-Military Coordination ...

challenging to weaponize these biological agents or cannot do so. Additionally, even in bioterrorism instances, the perpetrators were not States, but domestic actors. The criticism further mounts that biosecurity is rooted in anticipated threats that may or may not occur. While these criticisms are part of the discourse, some studies suggest that by improving biosecurity and bio-preparedness, responses to threats can improve significantly, even in times of natural disasters. ${ }^{33}$

Issues due to the control of information and deterrence, also prove to be problematic in discussing biosecurity. Control of information refers to the problems of dual-use, where existing research and information can be coordinated for malevolent or malicious purposes. To improve biopreparedness and response to biological threats, research on known biological warfare agents needs to be carried out. However, the research into these organisms can prove to be a two-sided sword. The very research that can bring benefit, can equally bring harm. Concerns over dual-use is no less a matter of debate for leading state's biodefense scientist. ${ }^{34}$

Moreover, since the problem of biosecurity is so vast, it can be hard to determine deterrence measures. While the BWTC does prohibit states from developing bioweapons, however, it does not define biosecurity, biopreparedness, or research limitations. In the meanwhile, commercial availability of biotechnology has made it easier for anti-state actors to manufacture viruses. Hence, some scholars claim that deterrence cannot play an overarching effective role. ${ }^{35}$ One, deterrent that is recognized is the improvement in responsiveness (i.e., bio-preparedness) through public

\footnotetext{
${ }^{33}$ Mary V. Davis et al., "Evaluation of Public Health Response To Hurricanes Finds North Carolina Better Prepared For Public Health Emergencies," Public Health Reports 122, no. 1 (2007): 20, doi:10.1177/003335490712200103.

${ }^{34}$ One of the many consequences of the Anthrax letter attacks, was the shutting down of the US postal service, hence showing the possible impact a bioterror attack can have.

${ }^{35}$ Margaret E. Kosal, "A New Role for Public Health in Bioterrorism Deterrence," Frontiers in Public Health 2 (2014): 278, doi:10.3389/fpubh.2014.00278.
} 
Securitizing Biosecurity: The Scope for Civil-Military Coordination ...

health sectors. ${ }^{36}$ Limiting dual-use, through controlling information and access to bioscience labs and facilities are other recognized deterrents.

However, while deterrence is only relevant to bioterrorism threats, the role of biosecurity is much broader than that and includes disaster management and emergency response. Though biosecurity threats require national and local security concerns, the scope of CIMIC in this regard is understudied herein. There is literature on humanitarian-civil-military efforts in natural disasters, but none so far has viewed this through the biosecurity lens. This study addresses this gap in the literature by assessing the scope for civil-military coordination in improving bio-preparedness vis-à-vis, improving public health in Pakistan. The next section provides a brief overview of the current state of biosecurity in Pakistan.

\section{Biosecurity: A Global Perspective}

Globally, the idea of biosecurity has been taken up by many governments and incorporated in policy decisions. Many states implement biosecurity measures by imposing serious border controls. Strict border control allows them to protect the life within their borders, from diseases and pests. New Zealand, can be taken as one example of a state that focuses on imposing strict border control. Similarly, in Japan the focus of biosecurity is on food and agriculture security and border control. While Australia also uses strict border control measures, their biosecurity policy is mainly guided by the "One Health" paradigm. ${ }^{37}$ The "One Health" paradigm, focuses on protecting all life within the Australian borders, including plants and animals. According to their website, the "One Health" paradigm also ensures that biosecurity is "everyone's job." Thus, ensuring an interdisciplinary approach to biosecurity. China has also recently adapted the "One Health" paradigm into its recent "Biosafety Laws of the People's Republic of China." 38 Moreover, in order to emphasize the various

${ }^{36}$ Koblentz, "From biodefence to biosecurity: the Obama administration's strategy for countering biological threats," 126.

${ }^{37}$ National Biosecurity Committee, "National Biosecurity Committee," Commonwealth of Australia, https://www.biosecurity.gov.au/about/national-biosecurity-committee.

${ }^{38}$ Ministry of Primary Industries, "Biosecurity," https://www.biosecurity.gov.au/ about/national-biosecurity-committee. 
Securitizing Biosecurity: The Scope for Civil-Military Coordination ...

dimensions of biosecurity, we need to understand the various factors that can contribute towards it, which include -- agriculture \& livestock farming, and human migration. Agriculture and livestock farming have been used as methods of spreading disease since ancient history. Some of the earlier examples of biological warfare were when the Mongols would spread disease amongst the livestock, resulting in deaths. Similarly, human migration patterns also pose a significant threat to biosecurity, as people travelling from various places carry parasites along, which can mutate into harmful diseases. Countries that focus on border control and stricter immigration policies, such as Australia and New Zealand, are also considered to have better response mechanisms.

On the other hand, in Canada, biosecurity entails the implementation of the Human Pathogens and Toxins (HPTA), the Human Pathogen and Toxins Regulations (HPTR). Certain sections of the Health of Animals Act and the Health of Animals Regulations (HAA/HAR) are also enacted upon. ${ }^{39}$ All these acts and regulations are implemented by bodies responsible for "biosafety" planning, pathogen security, pathogen management and stakeholder engagement.

In the USA, the main body responsible for biosecurity is the State Department, which then works with the Center for Disease Control, National Institute of Health, the Department of Health Services and the Department of Defense. A lot of biosecurity policy focuses on the protection of marine life in the US, while emphasizing on food and agriculture. Perhaps, the US example will help elucidate how biosecurity requires an all-encompassing and interdisciplinary approach. Moreover, the response and preparedness for any instance of CBRN attacks lies with the Department of Defense. ${ }^{40}$ The United Kingdom can also be taken as an example to understand how biosecurity requires a more comprehensive

\footnotetext{
${ }^{39}$ Government of Canada, "About the Centre for Biosecurity," https://www.canada.ca/en/public-health/services/laboratory-biosafety-biosecurity/aboutcentre-biosecurity.html.

${ }^{40}$ US Department of State, "Biosafety and Biosecurity," https://www.state.gov/biosafetyand-biosecurity/
} 
Securitizing Biosecurity: The Scope for Civil-Military Coordination ...

and holistic approach. The government of the UK focuses on biosecurity and the role that industry and academia plays in it. ${ }^{41}$

\section{Background: Biosecurity in Pakistan}

Pakistan has been a signatory of the Biological Weapons \& Toxins Convention (BWC) since 1972 and ratified in 1974. Pakistan is also a signatory to the Cartagena Protocol on Biosafety, which defines protocols for safe trans-boundary movement of organisms. Being a signatory to these conventions, Pakistan is prohibited from stockpiling biological agents; however, it does not impose any restrictions on these agents' research and development. It also has a comprehensive policy framework, paired with a sufficiently advanced research infrastructure. The policy framework includes policies like the Drugs Act (1976), Plant Quarantine Act (1976), Animal Quarantine Act (1979), Pakistan Environment Protection Act (1997), Pakistan Export Control Act (2004), Sanitary and Phytosanitary Agreement (WTO), International Health Regulations (2005) and the National Internal Security Policy (2014); other biosafety related policies include Pakistan Biosafety Rules (2005) and National Biosafety Guidelines (2005) ${ }^{42}$ While the policymakers seem to have done their part in building a biosecurity program, the lack of implementation of these policies exposes a bigger hole in Pakistan's attempt to formulate a biosecurity policy and structure. Meanwhile a situational analysis of Pakistan's National Biosafety and Biosecurity Policy (2017) underscores the following:

1. Some biosafety awareness and practices are in place, showing the laboratories' concern in the domain, but there is no centralized, structured Biosafety and Biosecurity Management System in place.

\footnotetext{
${ }^{41}$ HM Government, "UK Biological Security Strategy," https://www.gov.uk/ government/publications/biological-security-strategy.

${ }^{42}$ Ali Talha Khalil and Faouzia Tanveer, "Pakistanis Bio-Preparedness with Regard to Biosecurity, Biodefense Strategies and Policy Measures," Journal of Bioterrorism \& Biodefense 06, no. 01 (2015): 2, doi:10.4172/2157-2526.1000132.
} 
Securitizing Biosecurity: The Scope for Civil-Military Coordination ...

2. Profound attention is required in the area of qualified human resource with relevant education and training. Some training programs are being elaborated to train biosafety experts but still the basic trainings in biosafety are lacking for staff and no competency assessments are being performed to ensure acknowledgement of these practices by the staff. Pakistan Biosafety Association (PBSA) is elaborating awareness and trainings, which remains insufficient at larger scale.

3. Maintenance of critical protective equipment is not up to requisite standards, exposing the staff handling the hazardous material to risks.

4. Waste disposal management is also weak, with no national legislation in place for the infectious material disposal, putting at risk not only the staff but the environment and the communities too.

5. There is no occupational health for the staff, in order to protect and cure them from potential laboratory acquired infections.

6. In general, there are weak area prevention measures in place, putting at risk all personnel working in the institutions. ${ }^{43}$

Additionally, other way of assessing the effectiveness of these policies is to use the Global Health Security Index. The index measures effectiveness of policies, over six categories, which include:

a. Prevention of the emergence or release of pathogens.

b. Early detection \& reporting for epidemics of potential international concern.

c. Rapid response to, and mitigation of the spread of an epidemic.

d. Sufficient \& robust health system to treat the sick \& protect health workers.

e. Commitments to improving national capacity, financing and adherence to norms.

f. Overall risk environment and country vulnerability to biological threats.

\footnotetext{
${ }^{43}$ National Laboratory Biosafety \& Biosecurity Policy Islamic Republic of Pakistan, December 2017. National Laboratory Working Group Ministry of National Health Services Regulations \& Coordination Government of Pakistan, https://www.nih.org.pk/national-laboratory-biosafety-biosecurity-policy/
} 
Securitizing Biosecurity: The Scope for Civil-Military Coordination ...

With these indices, Pakistan is ranked 105th amongst the countries with a collective score of 35.5 , which was below the average score. ${ }^{44}$ Nonetheless, even if one subscribes to the index, Pakistan's disaster response and mitigation was observed to be above average (as will be demonstrated in subsequent section), however, the prevention of emergence or release was well below average. This can be used to support the argument that Pakistan's current biosecurity framework is insufficient. Furthermore, it must be understood that most of the legislations are geared at developing biosecurity and biosafety risk assessment methodologies. Yet, safety assessment is restricted to laboratory safety from high-risk pathogens. However, even then, there is no collective, central or federal database or directory for the various pathogens held in the many labs in Pakistan.

Even with this policy in place, Pakistan's vulnerability to biosecurity threat remains and calls for the civil-military cognizance and attention. The following discussion dissects few areas of vulnerability.

Firstly, its large and growing population is both a valuable human resource and endowment, but with the state of the health system and capacity to manage health-related biosecurity, Pakistan will largely be under pressure. The experience of oxygen shortage contributed to the number of unwarranted Covid-19 death rate across the country. Though this needless circumstance was complicated by the vicious syndicate hoarding the essential necessity to save lives. Invariably, this explicates why combating the threat of biosecurity must include the sensitization of the general public - public awareness is a cogent mechanism, requiring greater cognizance than the havoc emanating from the threat of biosecurity. In furtherance to the intersection between health systems, national hygiene, and health-related biosecurity threat, vector borne

\footnotetext{
${ }^{44}$ The Global Health Security Index, Global Health Security Index Building Collective Action and Responsibility (Washington: Nuclear Threat Initiative, 2019), https://www.ghsindex.org/wp-content/uploads/2020/04/2019-Global-Health-SecurityIndex.pdf
} 
Securitizing Biosecurity: The Scope for Civil-Military Coordination ...

diseases are one major threat to biosecurity. Unless the means of spread is identified, the disease may have become widespread. In Pakistan, there are frequent outbreaks of vector borne diseases such as, Dengue and Malaria, which often receive government response (local, provincial and central), that requires more enhancement -- to curb these outbreaks. For instance, at the outbreak of Dengue 2021, ${ }^{45}$ once cases started emerging, district health officers conducted a survey to identify breeding spots. However, issues became complicated in terms of stockpiling anti-malarial drugs and ensuring supply to all the areas that experience a greater number of cases.

Secondly, behaviors towards vaccines are also part of the biosecurity framework. In Pakistan, other than the urban areas, segment of the society has been anti-vaccine and the anti-polio phenomena is a case of reference. While the sentiment may have stemmed from multiple variables, unattendance on the part of the civil-military bureaucracy may become injurious to the entire health of the nation. Other than the polio, the recent outbreak of Covid-19 pandemic further added to the repugnant sentiment, as segments of the society believed the Covid-19 was part of a bigger 'Western' schematic tool to enslave the world. Hence, behaviors towards immunization campaigns seemingly come under the ambit of biosecurity and requires serious attention by the civil-military authorities. Furthermore, drug use has been studied to be another threat to biosecurity - where the use of various drugs and antibiotics has resulted in the emergence of more drug-resistant pathogens. According to Katona and Scheld, these factors contribute to the emergence and re-emergence of infectious diseases and pose a threat to biosecurity. Meanwhile, other forms of threats to biosecurity may manifest in the form of pathogens that can affect plants and animals resulting in lasting food shortages and famine. In Pakistan's context, as an agrarian economy, with a largely rural population, a pathogen that affects the agricultural yield would impact a

45 Dawn, "Rising Dengue Cases," September 24, 2021, https://www.dawn.com/news/ 1648071/rising-dengue-cases 
Securitizing Biosecurity: The Scope for Civil-Military Coordination ...

large section of the population. This further underscores our argument that sees an intersection between biosecurity threats to food security.

Thirdly, the tendency of inappropriate or intentional malicious or malevolent use of potentially dangerous biological agents or biotechnology by an adversary is a plausible possibility. Pakistan has been a victim of enemy infiltration, recently and in the past. Enemy spies operating in Pakistan have galvanized anti-state and secessionist sentiment amongst various segments of the society, who claim marginalization. They are resultantly disgruntled towards the state. The role of enemy spy in Baluchistan is a reference point. ${ }^{46}$ In recent times, secessionist sentiments have turned more violent and such can further metamorphose into a gruesome situation. Civil-military leadership at both provincial and central level must set the apparatus (preparedness) for the eventuality of a malevolent use of potentially dangerous biological agents or biotechnology by the 'aggrieved - marginalized,' supported by the enemy state, either operating cells within or beyond the shores of Pakistan. The possibility of anti-state elements, weaponizing biosecurity threat against the state should be taken thoughtfully and thus the readiness to contain and combat the threat. In a similar token, Pakistan cannot claim to be insulated from the concern of 'dual-use' - of which existing research and information can be coordinated for malevolent or malicious purposes. Terror-minded persons with certain degree of know-how of biological agents -- pathogens or biotechnology or having access to where the agents are developed and produced can be tempted, lured, forced to put them into terror utility. This is not a farfetched supposition, as well-educated persons from IVY Pakistani tertiary institutions have been apprehended for violent extremism and terrorism cases ${ }^{47}$ Indeed, this should be an eyeopener for the government to become more sensitive towards such kind of

46 Aamir Latif, "Pakistan, India locked in Spy Row," Anadolu Agency, April 16, 2017, https://www.aa.com.tr/en/asia-pacific/pakistan-india-locked-in-spy-row/797718

${ }^{47}$ Zahid Shahab Ahmed and Qamar Abbas Jafri, "Drivers of Violent Extremism in Higher Education Institutions of Pakistan," Dynamics of Asymmetric Conflict (2020):1-16. DOI: $10.1080 / 17467586.2020 .1821068$ 
Securitizing Biosecurity: The Scope for Civil-Military Coordination ...

persons, who may possibly become a threat to national security, based on their know-how and readiness to activate the threats of biosecurity.

Fourthly, one other area of serious concerns is the area of food security. While Pakistan is not entirely an autarky -- self-producing country, it often faced food challenges, on account of both domestic and external factors and sometimes factored by structural variable. Food mobility through porous borders can carry threat of biosecurity. Pakistan gets some of her food stuff from across the border. While most states would tend to be responsible in this regard, yet, the possibility of introducing harmful pathogens through food produce for malevolent attempt cannot be a ruledout equation. In this backdrop, it is imperative that Pakistan border security gets more fortified, while coordination and cooperation of stakeholders - involving health workers and biologist get more consolidated and intensified. Border protection should not be primarily dominated by immigration officer, anti-narcotic and custom. The consideration for biosecurity must be integrated into the whole scheme of border protection.

Arguably, this study opines that these lacunas, especially the lack of implementation of policy, results from two factors (i) the gap between the state and the discipline, and (ii) the differences in understanding of biosecurity.

\section{Gap between the State and the Discipline}

The gap between academics and the state is relevant to all fields and disciplines in Pakistan. Policymakers and technocrats are frequently at odds when it comes to formulating policies. At its very core, this problem stems from Pakistan being a security state, which frequently assesses opportunities and policies in light of its relations with its neighbours and generally from a security perspective. Hence security is the priority in all cases and takes precedence when it comes to setting matters on the agenda, and implementing and monitoring policy. As evidenced by the interviews conducted - the policy regarding biosecurity is very loosely defined - one respondent said "there are several policy documents 
Securitizing Biosecurity: The Scope for Civil-Military Coordination ...

available on the topic of biosafety, but careless implementation stems from the fact that there are no consolidated databases, which can help the state monitor the number of toxins and biological agents gathered in labs." According to them, the consolidation of a database will allow for better governance of available agents. However, the gap between the state and the discipline has become a barrier to effective policymaking with regards to these rules.

Moreover, a review of documents issued by the PBSA, MOCC and Pakistan's Environmental Protection Agency, also evidences the lack of understanding and depth at the policy level. While there is very little mention of "biosecurity" in policy documents, there is still more data and legislation concerning "biosafety" as opposed to "biosecurity. One reason why biosecurity has not come to the forefront of policy debates is that Pakistan faces no such threats in a traditional security sense, as India is a signatory to the BWC and hence cannot develop or stockpile bioweapons or toxins and does not pose a threat in the traditional sense. ${ }^{48}$ One 2011 evaluation of the implementation of the BWC noted that Pakistan has made efforts to inculcate biosafety in its Policy framework however, even in that assessment Pakistan's biosecurity framework is largely absent. ${ }^{49}$ Although in several places in the literature, one does come across "biosafety \& biosecurity" in Pakistan's context, but the emphasis has remained on biosafety, alluding to the greater problem - i.e. lack of understanding on what constitutes "Biosecurity". ${ }^{50}$

\section{Difference in Understanding of Biosecurity}

The second issue identified is the difference in the general understanding of the term biosecurity, very often in the minds of policymakers and

\footnotetext{
${ }^{48}$ Zafar Jaspal, "Biosecurity and Pakistan: A Critical Appraisal," NDU Journal 29, no. 1 (2015): 5 .

${ }^{49}$ Aamer Ikram, "Case Study I: Biosafety and Biosecurity in Pakistan," in Improving Implementation of the Biological Weapon Convention, ed. Piers Millet. New York: UNIDIR, 2011.

${ }^{50}$ Muhammad Sikander G. Khan, et al, "Survey of Biorisk Management in Clinical Laboratories in Karachi, Pakistan,". Applied Biosafety 17, no 4(2012):198-207.
} 
Securitizing Biosecurity: The Scope for Civil-Military Coordination ...

technocrats; the term is taken to mean biosafety - as in the safety rules and protocols that must be adhered to when handling biotechnology and working with parasites, matter, and living organisms. However, as mentioned earlier, biosecurity is broader than biosafety,${ }^{51}$ and while biosafety is limited to the labs and workspaces, biosecurity encompasses all aspects of life. This difference in understanding reflects one of the main reasons' policymakers are more reluctant to address biosecurity issues because they frequently think it is out of their domain and has a minimal scope. Even the military establishment views biosecurity from a very traditional viewpoint, limiting it to instances of bioterrorism and biological warfare, which they argue are very implausible because India is a signatory to the BWTC. Moreover, to further define the scope of this paper, it is necessary to understand the impact biosecurity can have beyond instances of war and terror.

Ultimately, in order to understand the impacts of biosecurity and the meaning of it, within the employed meaning of it and within the scope of this paper, we must understand it from the impact that disease can have on policy. The recent closing of borders between Pakistan and Afghanistan can be used as an illustration of the impact of disease on policy and the movement of biological beings. It also further warrants the need to approach biosecurity from a national security standpoint.

This seemingly simple difference translates into the divide between the state and the discipline and keeps the policymakers from understanding the significance of and the comprehensive set of policies required to strengthen biosecurity in Pakistan. It also limits the number of sectors willing to participate in biosecurity, and assumes that the complete onus of biosecurity lies with the health sector.

Pakistan's health sector classifies as a mixed health system, which hosts public and private institutions. The public health sector is multi-tiered, and

\footnotetext{
${ }^{51}$ Stephen J. Collier, Andrew Lakoff and Paul Rabinow, "Biosecurity: Towards an Anthropology of the Contemporary," 6.
} 
Securitizing Biosecurity: The Scope for Civil-Military Coordination ...

due to a vast rural majority, the local public health institutions face different challenges. Sania Nishtar, Special Assistant on Poverty Alleviation and Social Safety to the Prime Minister of Pakistan, identifies numerous problems in the health care system, some of which are the lack of transparency in governance, the lack of funding and greater influence of alternative medicine. ${ }^{52}$ According to her, Mixed Health System Syndrome (MHSS) refers to when the health sectors delivery is inefficient and unresponsive due to an unclear regulatory framework and each tier of the system operating at its own levels and in a more remote area, there have been several cases of ghost workers, which she attributes to the absence of competitive salaries in public health. Furthermore, public health workers also have sufficient occupational hazards that severely affect motivation and morale. Many scholars, who study the public health sector and its delivery mechanisms, note instances where the locals have attacked public health workers, going door to door to administer polio vaccines ${ }^{53}$ Similarly, the ghost worker' phenomenon can also be seen as a result of these dangers, as even though efforts have been made to build hospitals or health centers in the most remote areas of Pakistan, people continue to rely on alternative medicine, such as homeopathy or the traditional daees ${ }^{6}$ and hakeem for their health-related queries and concerns ${ }^{54}$ Dr. Seema Raza Tariq, a public health administrator, said:

The availability of alternative systems isn 't necessarily a bad thing, what's bad is that there is no regulatory mechanism for it, which leaves many of the uneducated and poverty-stricken people at risk of being exploitedthe "neem hakeems" (inexperienced faith healers), can cause serious harm to a person's health. ${ }^{55}$

\footnotetext{
52 Sania Nishtar, "The Mixed Health System Syndrome," Bulletin of the World Health Organization 88, no. 1 (2010):76, doi:10.2471/blt.09.067868.

53 Jaspal, "Biosecurity and Pakistan: A Critical Appraisal," 25.

${ }^{54}$ Sania Nishtar, "The Mixed Health System Syndrome," 45.

${ }^{55}$ Dr Seema Raza Tariq interviewed on August 18, 2020.
} 
Securitizing Biosecurity: The Scope for Civil-Military Coordination ...

Along with the struggles of the health system in Pakistan, biosecurity barriers also include the dual-use problem as previously mentioned. This problem includes the academic discipline that feels that there is not enough inter-sectoral coordination and support for Pakistan's biotechnology industry. One of the academics from the field of Biosciences, Mahnoor Qureshi said:

\section{The COVID-19 pandemic is one instance where our field has received a lot of attention, we are receiving funds and research grants, but the thing is that even in these instances, the gap between the policy and the discipline is real - it's not that Pakistan isn't conducting research, or that we don't have regulatory bodies - in spite of having all that, we find it difficult to translate the need of the hour into policy. ${ }^{56}$}

This problem of dual usage means that security threats are on the horizon at any given moment. For instance, in the US, in order to curb problems of dual-use, the Obama administration decided to introduce strict ethical and moral codes, along with clearance levels and controlled access, that was granted after thorough background checks had been conducted. ${ }^{57}$ Polarization and extremism have been on the rise. In countries where sensitive information related to biotechnology is not appropriately secured, it is easier for radicalized individuals to access and use it to fulfill their nefarious goals (of incapacitating a group of people or a locality just wreaking havoc). Controlling access to such resources and information might serve as a deterrent against such technology's illicit utility by either nefarious non-state actors or people having a legal right to the technology but misusing it.

\footnotetext{
${ }^{56}$ Mahnoor Qureshi interviewed on September 11, 2020.

${ }^{57}$ Koblentz, "From Biodefence to Biosecurity: The Obama administration's Strategy for Countering Biological Threats," 133.
} 
Securitizing Biosecurity: The Scope for Civil-Military Coordination ...

Until this juncture, the discussion looks at the problems that set the background for biosecurity in Pakistan and the conundrum that the state is encountering. On the one hand, greater transparency and availability of information stands to improve the state of public health through raising awareness, educating people and improving accountability measures for public health workers, when it comes to bioscience research, too much transparency and access pose the problem of radicalized individuals misusing the information to serve their own purposes. A balanced approach must be struck between health and biosecurity "security and governance" aspects, which can only be done through civil-military coordination. The next section explains the role that civil-military coordination can play in improving biosecurity.

\section{Information, CIMIC and Biosecurity}

Civil-military coordination within public health is no new venture; the Pakistan Army has managed to build its own health service delivery mechanism that produces and recruits' doctors from all over the country. ${ }^{58}$ The army has also provided health services to areas ridden with conflict, for instance, the setting up of camps with mobile health units in North Waziristan.

Figure 1 the ideal balance between civil institutions and the military

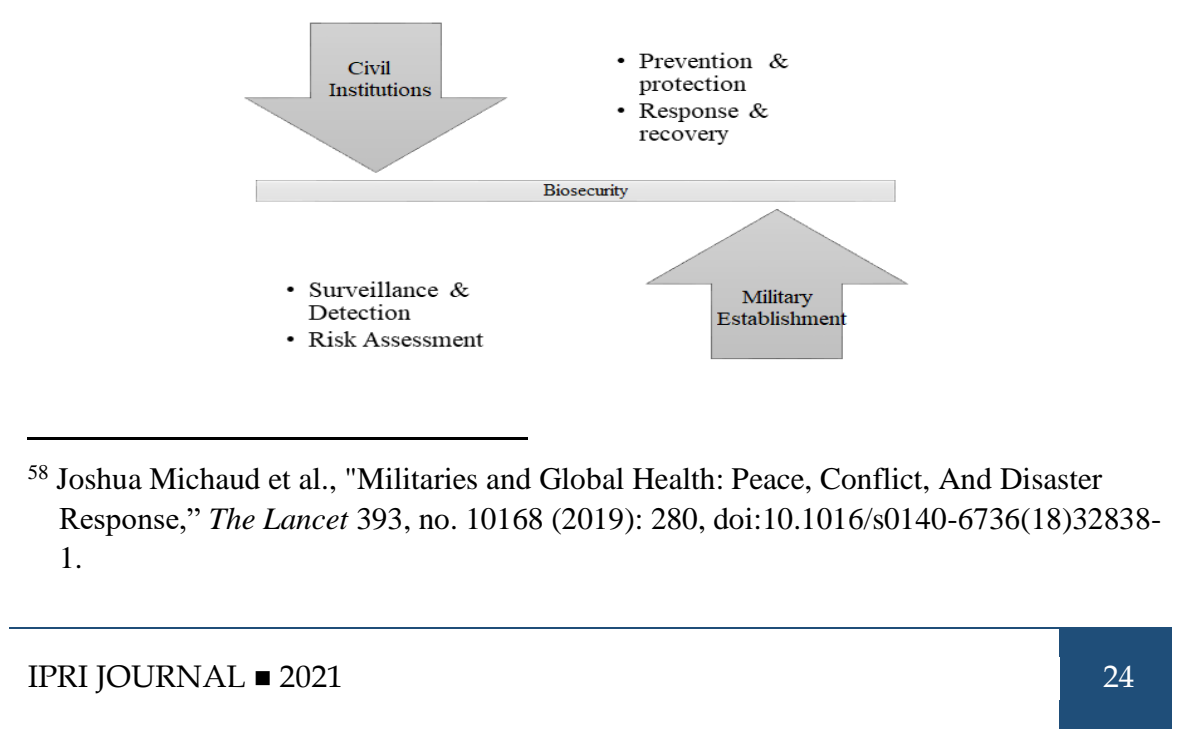


Securitizing Biosecurity: The Scope for Civil-Military Coordination ...

However, most militaries are given charge of establishing systems during the conflict, such as healthcare systems, worldwide. In Pakistan, the case is different; the National Disaster Management Authority that oversees disaster management in the country comes under military control. ${ }^{59}$ This disaster management model is relatively standard in countries with large armies because of the sizable share of the military's budget. Being one of the most organized institutions, unsurprisingly during disaster and conflict, the military has played a significant role as the most reliable leading institution to lead and save the people, however, what role does it play during peacetime? According to one military official - "Peace in Pakistan is possible because of the efforts and sacrifices of our Jawaans, we see the military may provide health services and preparedness efforts when a community is engaged in conflict, but it should not completely abandon its role in these sectors during peacetime." During peacetime, the military should not be fully responsible for setting up the public health system, but it should help the public health sector improve its capacity to respond and prepare. ${ }^{60}$ Civil-military coordination in this context would require a model to operate and evenly distribute this responsibility.

Similarly, in times of conflict, the military may need to dedicate its intelligence gathering and surveillance resources to confront the opposition, during peacetime, it must utilize these resources for risk assessment and surveillance and detection. Risk assessment or threat awareness would mean the military recognizes the problems of dual-use and working with research organizations to prevent misuse. While the bioscience discipline continues to do their research, the military should understand threats and risks to see if there can be any possibility of the research being used for malicious intent. If that is the case, then the military should inform the civil institutions. Moreover, defining different

\footnotetext{
${ }^{59}$ Khalil and Tanveer, "Pakistanis Bio-Preparedness with regard to Biosecurity, Biodefense Strategies and Policy Measures," 6.

${ }^{60}$ Joshua Michaud et al., "Militaries and Global Health: Peace, Conflict, and Disaster Response," 277.
} 
Securitizing Biosecurity: The Scope for Civil-Military Coordination ...

security risk levels - as already defined by the PBSA and other relevant bodies should be considered seriously. Subsequently, surveillance and detection are yet another aspect of strengthening biosecurity that the military can facilitate. Surveillance and detection include gathering information and intelligence from various sources, such as regional databases like Emerging Infectious Diseases. While the military can use its information surveillance and threat assessment models to create a more proactive approach towards biosecurity threats, civilian institutions should take the responsibility of prevention and protection and response and recovery.

On the one hand, prevention and protection include immunization campaigns, and additional preventive measures such as improving hygiene and nutrition. On the other hand, response and recovery include immediate response in case of an outbreak and how quick a system can recover from it. The civil institutions should take lessons from the military, in order to be able to build effective response and recovery methods, which include quarantining facilities and efficient response mechanisms from public health. While the roles seem to be equitably divided between the civil institutions (such as public health) and military establishments (as shown in Figure 1), neither can perform effectively without the discipline's support. The discipline conducts research and generates information that can then be used by the military to assess threats and understand what to look for when conducting surveillance and detection exercises. Similarly, when designing response and recovery frameworks and prevention and protection mechanisms, it is the discipline that provides the most efficient and recent technology to build these systems.

Interestingly, the Corona Virus (COVID-19) pandemic has exposed how pressing and demanding is the case of biosecurity. It has attracted attention towards issues of global health and biosecurity. Amidst the pandemic, medical professionals, bio-scientists, civil government, and the military have all bonded together to respond to the threat as needs arise. According to Muhammad Abdullah, a senior government official: 
Securitizing Biosecurity: The Scope for Civil-Military Coordination ...

I believe Pakistan's response has been one of the best ones that we have seen - if you talk about biosecurity, it really can be used to explain how a multi-sectoral approach can benefit everyone. During the lockdown all sectors adapted with great speed - what's really remarkable here is that the general masses also complied with all the protocols. ${ }^{61}$

Civil governments have introduced policies and response methods to curb disease spread, while bio-scientists have dedicated their resources towards creating testing kits and vaccines. Public health officials, military personnel, and civil governments relied on the research conducted on the COVID-19 virus strain, to decide how to proceed with caution. However, while these were times of crisis, as the world moves into the post-COVID times, there is a need to create greater response mechanisms to address any future infectious disease or viruses.

Figure 2: Knowledge generation is at the core of threat-awareness, detection and response

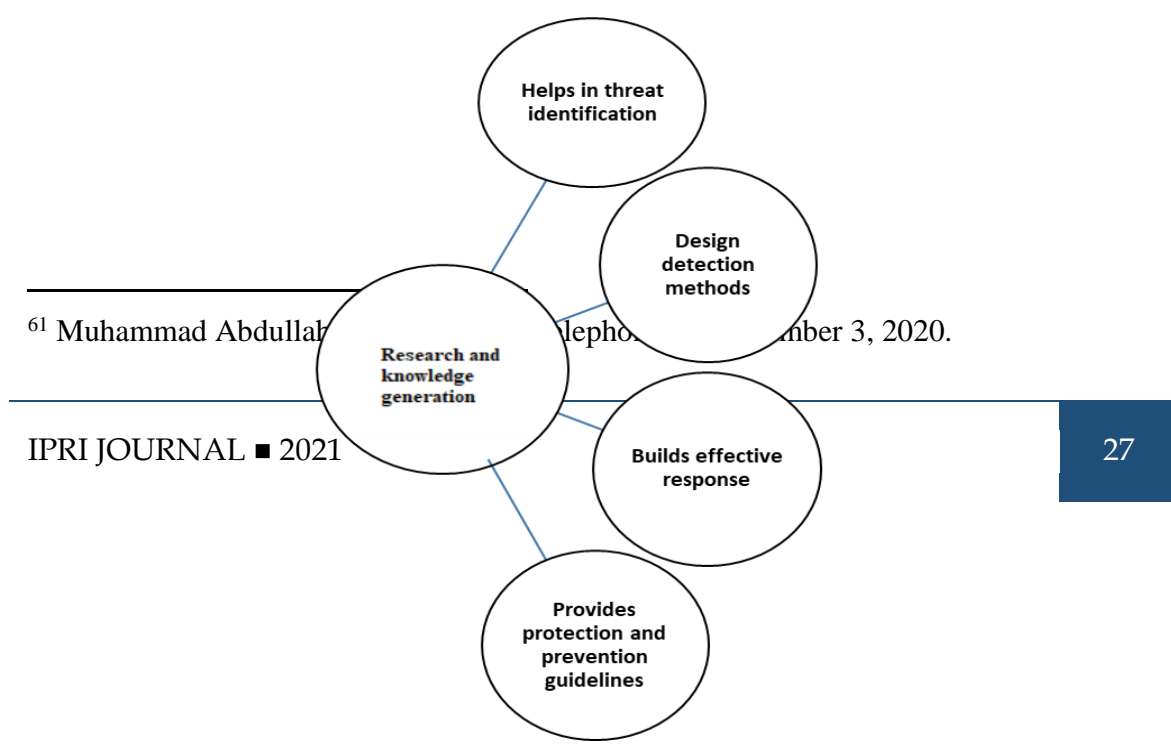


Securitizing Biosecurity: The Scope for Civil-Military Coordination ...

\section{Methodological Considerations}

The methodology for this research involved conducting expert interviews, transcription and analysis of those interviews, and drawing conclusions. The interviewees were divided into four groups: (1) Security and military people, (2) Public Health Administrators, (3) Academics, (4) Government officials and policymakers. The target groups so evaluated the level of awareness of the subject of biosecurity in each sector. Effective biosecurity requires a multi-sectorial approach that does not limit itself to the public health or security domain. Hence, a minimum of three persons from each group were interviewed. Security and military personnel mostly included people with a military background, while the interviewed public health administrators were quizzed to have their view on biosecurity and how it can be improved. Academics that were contacted were people researching biosafety and scholars of Peace and Conflict Studies. Similarly, government officials that were contacted included mostly policymakers and bureaucrats. Purposive sampling was employed for this research mainly because of the timing. The research was conducted during the peak of the COVID-19 wave in Islamabad, Pakistan - hence, keeping in view the safety protocols and restrictions on meetings, the interviews were conducted over the phone, from a small number of people.

The wide array of interviewees with very different backgrounds helped identify the problems each sector faces when designing biosecurity policies and a national biosecurity plan. The interviews were mostly unstructured. However, two questions that were asked from all the interviewees were 'what they think biosecurity is?' and 'how could coordination between the civilian government and the military establishment improve the state of biosecurity in the country? Other questions included "whose responsibility should biosecurity be?" "What is the likelihood of the issue of dual-use becoming a threat to security?" "What is the role of information in biosecurity?" and "What are the plausible links between conflict and biosecurity?" 
Securitizing Biosecurity: The Scope for Civil-Military Coordination ...

Limitations to the research were the general confusion that the interviewees had during the pilot study, separating biosecurity and biosafety concepts. Hence, this explicates one reason why interviews had to be largely unstructured, as this allowed the interviewees to share their knowledge as per their comfort and perspective. Additionally, some privacy concerns were also raised on the interviewees' part, and some did not allow the interviews to be recorded. The following section elaborates the findings of the study and concludes.

\section{Discussion and Findings}

Prior to dwelling on the findings from the interviews, we find it apt to enunciate the state of CIMIC in Pakistan vis-à-vis NTS, within the larger framework of biosecurity. It is imperative to highlight the depth of biosecurity, and the reason why CIMIC can enhance preparedness against impending threats.

Like the rest of world, Pakistan is vulnerable to the attendant consequences of climate change, ${ }^{62}$ there is a growing impact of receding Himalayan glaciers on the Indus River system, shortage in water reservoirs, deforestation, floods and droughts, and its attendant food insecurity. To address these issues, the country has instituted Pakistan's Task Force on Climate Change. According to UNDP Climate Change Adaptation, Pakistan has shown serious commitment and has taken (domestic, regional and international) efforts to combat the menace of climate change. ${ }^{63}$ While the challenges persist, yet, Pakistan has been hailed for its ten billion trees tsunami project, ${ }^{64}$ eco-friendly -- "Say No to

\footnotetext{
${ }^{62}$ Mansoor Raza, "Response to climate change," The News, February 22, 2021, https://www.thenews.com.pk/print/793634-response-to-climate-change

${ }^{63}$ UNDP Climate Change Adaptation: Pakistan, https://www.adaptationundp.org/explore/pakistan

${ }^{64}$ Chloé Farand, "Pakistan explores debt-for-nature scheme to accelerate its 10 billion tree tsunami," Climate Home News, April 16, 2021, https://www.climatechangenews.com /2021/04/16/pakistan-explores-debt-nature-scheme-accelerate-10-billion-tree-tsunami/
} 
Securitizing Biosecurity: The Scope for Civil-Military Coordination ...

Plastics" campaign, ${ }^{65}$ and other CIMIC efforts, during climate changeinduced natural disasters. ${ }^{66}$ The demonstration of CIMIC is not only true for the stabilization of erstwhile FATA - Pakistan, it is equally evident during the occurrence of natural disasters in the country. Tughral Yamin argues that under the banner of National Disaster Management Authority (NDMA), the civilian and military administrations jointly strategized "standard contingencies for managing flood and earthquake relief." The role of NDMA has continued to be salient and important since the 2005 earthquake disaster, which saw the military help with delivering relief packages and organizing a disaster response. This equally has been true for subsequent natural disasters that rampaged the country. ${ }^{67}$

CIMIC has proven to help improve Pakistan's response in disaster management. For instance, the response that Pakistan got when it formulated its COVID-19 policy, can be taken as one example to understand the role that CIMIC has played to help build capacity within the civilian structure. In building response to COVID, the military offered detection and data collection facilities, in the National Command Operation. Moreover, during the most recent third wave, the army was also used to impose government policy, although "smart lockdowns" were mainly implemented by the local law-enforcement agencies. The smooth response earned Pakistan praise and adulation. ${ }^{68}$ While the WHO has applauded Pakistan's response to the Covid-19 during the first wave. ${ }^{69}$ In addition to helping set up isolation camps, the army also "deployed troops

${ }^{65}$ Mushahid Hussain, "Pakistan's Battle against Climate Change,” ReliefWeb, April 17, 2019, https://reliefweb.int/report/pakistan/pakistan-s-battle-againstclimate-change

${ }^{66}$ Shafqat Kakakhel, "Climate Change: Impacts and Security Implications for Pakistan," Islamabad Papers - ISSI, no.28 (2016):1-41.

${ }^{67}$ Tughral Yamin, "Civil Military Relation and Stabilization in Federally Administered Tribal Areas (FATA), Pakistan,” NUST Journal of International Peace \& Stability II, no. 2 (2019):45-54.

${ }^{68}$ AFP, "WHO Chief Lauds Pakistan for Suppressing COVID-19 While Keeping Economy Afloat," Dawn, September 29, 2020, https://www.dawn.com/news/1582311

${ }^{69}$ Ikram Junaidi, "WHO praises Pakistan's handling of Covid-19 Pandemic," Dawn, September 11, 2020, https://www.dawn.com/news/1578971 
Securitizing Biosecurity: The Scope for Civil-Military Coordination ...

in 16 major cities to assist civilian authorities in enforcing measures to stop the surge in COVID-19 cases. The soldiers will make sure that people are following standard operating procedures (SOPS), including social distancing and masking." ${ }^{70}$ Besides, one of its premier universities - National University of Sciences and Technology (NUST) has developed scientific apparatus to help address the challenges of Covid-19. ${ }^{71}$

In respect to the conducted interviews, our first finding was that there was no reflection of biosecurity in Pakistan's policy -- it was noted by several interviewees that the scope remained limited to the understanding of biosafety within the larger canvas of biosecurity. Until the outbreak of the Covid-19 pandemic, there existed no civil-military coordination or preparedness for such a pandemic. The unpredictable nature of the pandemic forced and brought forth some form of coordination. This further reiterates Khan, Tanveer, and Muhammad's concern vis-à-vis pandemic and laboratory biosecurity, "Pakistan has yet to fully develop and implement approaches for risk assessment, frameworks for oversight and regulation, or tools and procedures for monitoring and reporting situations in which misuse of biological materials might occur."72

The next finding that became evident during the interviews was the diversity of understanding vis-a-vis biosecurity. Academicians, both social as well as bio-scientists, had a good understanding of biosecurity. For the social scientist - biosecurity is the protection of life and sovereignty, through protection and promotion of health. ${ }^{73}$ In contrast, for the bio-scientist, biosecurity is a broad term, entailing the biosafety guidelines as in the handling of biological agents, it also includes the

\footnotetext{
${ }^{70}$ Mavra Bari, "COVID in Pakistan: Is army deployment an admission of failure?," $D W$, April 29, 2021, https://www.dw.com/en/covid-in-pakistan-is-army- deployment-anadmission-of-failure/a-57376149

${ }^{71}$ Shazia Mehboob, “Science: NUST’S Covid-19 Testing Kit,” Dawn, March 29, 2020, https://www.dawn.com/news/1544560

72 Tariq Khan, Faouzia Tanveer, and Javed Muhammad, "Improving Biosecurity in Pakistan: Current Efforts, Challenges, and Recommendations on a Multidimensional Management Strategy." Health Security 19, no 3(2021): 256

${ }^{73}$ Faisal Majeed, a university professor, interviewed on August 21, 2020.
} 
Securitizing Biosecurity: The Scope for Civil-Military Coordination ...

health and immunization of living organisms. ${ }^{74}$ Away from academia, the definition started changing in the practical applications. According to Dr. Shahid Afridi, a public health administrator, biosecurity meant immunization schemes and promotion of public health. ${ }^{75}$ Whereas to the policymakers and bureaucrats, it is "the protection of animals and agriculture, from pests and diseases." Most military personnel responded to the question with their understanding of biosecurity being "responses to instances of bioterrorism." 76 The extensive scope of biosecurity can be highlighted because each group was aware of and had some prior understanding of the term, but the meaning communicated was not precisely clear. This can be used to support the claim that civil-military coordination and overall, a multi-sectorial approach is needed in order to build an effective biosecurity program and to be able to design a streamlined definition.

As definitions varied, so did the perceptions of their role, bio-scientists and public health administrators acknowledged that their roles were important. When questioned about whose responsibility biosecurity should be, there were quite varied responses. Two military personnel who did not agree that they played a significant role in biosecurity did not agree with it being their responsibility. One of them said: "There are specific instances, where one is obliged to take up a role - it's not about whether you are qualified or not, but the responsibility of ensuring quality of life, and health is a collective responsibility that all institutions should work towards it." ${ }^{\text {77 }}$ Furthermore, the government officials maintained that "a secure Pakistan is everyone's responsibility." The government officials said that the responsibility of promoting biosecurity does not fall to one person; it belongs to all of us. ${ }^{78}$

\footnotetext{
${ }^{74}$ Bio-scientist, Aziz Jahangir interviewed on September 6, 2020.

${ }^{75}$ Dr. Shahid Afridi interviewed on August 21, 2020.

${ }^{76}$ Military Official interviewed on September 20, 2020.

${ }^{77}$ Military Official interviewed on August 20, 2020.

${ }^{78}$ Military Official interviewed on August 18, 2020.
} 
Securitizing Biosecurity: The Scope for Civil-Military Coordination ...

To improve coordination amongst the three groups, the next questions were to see if any of the groups faced common problems when it comes to performing their roles on biosecurity related issues. Bio-scientists and public health officials claimed that theirs were challenging fields to work in. For instance, Mahnoor Qureshi, a bio-scientist opines, "The laws exist, the bodies required to implement these laws, the PBSA is also there, but what is absent is the implementation of these laws."79 Lack of implementation of the biosafety guidelines, and all the red tape that doctors and researchers have to face, were among the most commonly cited issues. One public health administrator argues that "People do not recognize the effort of the public health workers, we have helped build many health centers and our people go door to door to give vaccines, but lack of funding is disheartening and demotivating." ${ }^{80}$ Interestingly, underscoring the nexus of biosecurity and challenges in the health sector, Dr Seema Raza, a public health officer connects the frequent strikes by young doctors in public hospitals (especially during the Covid-19) to existential threat. She asserts:

A public health sector is a perilous place for some, remember the doctor who got shot in the shoulder in BBH (Benazir Bhutto Hospital)? Even in the recent Coronavirus situation, doctors were starting to fear for their lives because people were threatening them (of their life) to get access to the bodies of their loved ones who had passed away due to corona. ${ }^{81}$

Public health officials also cited lack of transparency as a security concern, "In order to contribute positively to biosecurity, we need to ensure that administrators and doctors are on the same page and are guaranteed just as much security as any other profession." ${ }^{\text {"82 }}$ Response to

\footnotetext{
${ }^{79}$ Mahnoor Qureshi interviewed on September 11, 2020.

${ }^{80}$ Telephone interview with a Public Health Administrator on August 21, 2020.

${ }^{81}$ Dr Seema Raza interviewed on August 18, 2020.

${ }^{82}$ Ibid
} 
Securitizing Biosecurity: The Scope for Civil-Military Coordination ...

the question shed light on authority, transparency and how these influences the perception of public offices for the public Additionally, when public officials were asked about possible solutions to the issues of transparency and public perception, they reassured that - efforts are underway to improve access to information, and improve the perception of the people. ${ }^{83}$ Consequently, one bio-scientist suggested measures to curb misinformation. ${ }^{84}$ While in an earlier section, the role of information and knowledge generation was quizzed, this question supports the claim that information and education play a vital role in biosecurity.

However, when the discussion moved to address the dual-use problem and the possibility of curbing the adverse side effects, bioscience academics claimed a need for public-private partnerships in funding the sector. While dual-use problems for the people within the field do not seem very likely, they did manage to see the link between conflict and biosecurity. More so, to think over the possibility of the radicalized person using research information or resources at their disposal for malicious purposes is a long shot. "I don't think there is as great a risk, that it should warrant constant military monitoring." 85 Three of the interviewees also focused on the role conflict plays and how it connects with the concept of biosecurity. For instance, Faisal Majeed argues:

The state has a responsibility to provide health services to its people, areas where health and nutrition are not as easily accessible, are more likely to host anti-state sentiments, which is to say much of Pakistan is ruralized and there are already plenty of fissures, access to health is just another divide. ${ }^{86}$

From an ethnic or sectarian standpoint, the link between conflict and biosecurity would also warrant civil-military coordination, like

\footnotetext{
${ }^{83}$ Public Official interviewed on August 26, 2020.

${ }^{84}$ Interview with Alina Ali on September 3, 2020.

${ }^{85}$ Mahnoor Qureshi, telephone conversation with author, September 11, 2020.

${ }^{86}$ Faisal Majeed, a university professor, interviewed on August 21, 2020.
} 
Securitizing Biosecurity: The Scope for Civil-Military Coordination ...

intelligence, preparation, and prevention efforts should be undertaken throughout the country. The public health sector can learn a lot in terms of building responsiveness and intelligence gathering.

Finally, when the discussion came to the viability of civil-military coordination to build Pakistan's biosecurity, the public health administrators agreed that civil-military coordination would prove necessary, in terms of gathering intelligence and creating awareness of the threat. One of the public health administrators said: "I have studied from an army institute, and my friends even opted to become army doctors after our graduation, and although their trainings aren't the exact ones that army people receive - one can see how the system is geared to operate at maximum capacity and efficiency." 87 Another public health administrator, also agreed, she said "it's definitely a system we can adapt and work on together."

The civilian government and the military establishment would need to include other sectors on this too, the public health sector and their responsiveness may benefit from this if the state starts considering biosecurity as important to its sovereignty. ${ }^{88}$ Three of the respondents believed that the state should take the responsibility of improving biosecurity entirely on their own, as it is not the military's domain. Those who believed that there is no future of civil-military coordination in biosecurity in Pakistan attributed the responsibility of response, awareness, education, and protection to the state entirely, empowering local governments to handle an outbreak of viruses or related health issues quickly and efficiently. The army personnel did not seem very keen on dedicating resources for this purpose. For instance, a military official argued:

Kashmir isn't free yet, and you people want us to dedicate resources for these things, while there are

\footnotetext{
${ }^{87}$ Telephone interview with a Public Health Administrator on August 21, 2020.
}

${ }^{88}$ Telephone interview with a Military Officer on September 25, 2020. 
Securitizing Biosecurity: The Scope for Civil-Military Coordination ...

people who continue to criticize the army's involvement

in everything. Pakistan Army's intelligence gathering

and responsiveness has - improved significantly and

helped the country in many times of crisis. ${ }^{89}$

\section{Policy Recommendations}

\section{Shared Responsibility}

Given its nature, biosecurity must be treated with utmost and special attention, thus, CIMIC cannot afford to be either nonchalant or lackadaisical about the grave threats associated with it. The alacrity, seriousness, and sense of responsibility of civil-military bureaucracy can best be gauged through the prism and degree of preparedness, preventive measures, and responsiveness to biosecurity threat, which associated consequences may transcend the border of Pakistan and thereby become a diplomatic - regional debacle, as evident for the origin of the Covid-19 virus. ${ }^{90}$ To this end, CIMIC vis-à-vis biosecurity in Pakistan must embrace the Bland's theory of shared responsibility, which states that the civil and military bureaucracies are mutually responsible and accountable to the nation they serve, some of their responsibilities for control may merge, but not fused. The shared responsibilities are conditioned by a nationally evolved regime - meaning that, to protect Pakistan against the outbreaks of newly emergent and epidemic disease - such as the Covid-19 or against the inadvertent, inappropriate, or intentional malicious or malevolent use of potentially dangerous biological agents or biotechnology, including the development, production, stockpiling, or use of biological weapons, it is therefore incumbent on the civil and military authorities to work convincingly towards Brook's functional roles, which

89 Telephone interview with a Military Officer on August 20, 2020.

${ }^{90}$ Theodore C. Masters-Waage, Nilotpal, Jha, Jochen, Reb, "Covid-19, Coronavirus, Wuhan virus, or China virus? Understanding How to "Do no Harm" when naming an infectious disease," Front Psychology, 2020, doi: 10.3389/fpsyg.2020.561270. PMID: 33362626. Also see Katie Rogers, Lara Jakes, and Ana Swanson, "Trump Defends Using 'Chinese Virus' Label, Ignorin++++g Growing Criticism,” New York Times, March 1 8, 2021, https://www.nytimes.com/2020/03/18/us/politics/china-virus.html 
Securitizing Biosecurity: The Scope for Civil-Military Coordination ...

defines and measures the integrity of any authority on how best, is its performance level. Similarly, CIMIC in general and for biosecurity in particular, must correspond with Schiff's theory of concordance that argues "three partners - the military, the political elites, and the citizenry should aim for a cooperative relation that may or may not involve separation, but require it." As an important element of non-traditional security threat, defeating the voracious threats of biosecurity does not require the polarizing and competitive theorization of Samuel Huntington with regards to civil-military relations. ${ }^{91}$ Instead, CIMIC in Pakistan needs to embrace Morris Janowitz's subtle proposition, which requires the military to evolve with societal values and norms should be welcomed and adopted. CIMIC can only be effective when there is a blend of thoughts, ideas and norms. ${ }^{92}$

\section{Nation's Prestige}

In international relations, the capability of a state is measured by the quality and quantity of its hard and soft power. This capability, amongst other, translates into prestige and integrity. How a state responds to international event or incident is part and parcel of integrity. For instance, the Covid-19 pandemic originated in Wuhan - China, and China had to endure the attendant criticism and labelling. One might have expected that the international criticism and labelling will largely dent the standing of Beijing, instead on account of its approach to containing and combating the pandemic, China became yet another international discourse, its response to biosecurity - pandemic "has accelerated China's rise" 93 as a serious and capable state, to combat biosecurity threat such as the Covid-

\footnotetext{
${ }^{91}$ Samuel, Huntington, The soldier and the state: The theory and politics of civil-military relations, Harvard University Press, 1981.

92 Morris, Janowitz, The Professional Soldier: A Social and Political Portrait, Simon and Schuster, 2017.

93 Hanns Günther Hilpert and Angela Stanzel, "China - Winning the Pandemic... for Now," Stiftung Wissenschaft und Politik-German Institute for International and Security Affairs, 2021. doi: 10.18449/2021C01
} 
Securitizing Biosecurity: The Scope for Civil-Military Coordination ...

19 pandemic. ${ }^{94}$ China's grabbed international prestige and integrity would never have been possible without "quick and strong measures in selfprotection, mobility control, resource allocation, professional health care, and disinfection, under the organization of the government and the cooperation of all the Chinese people." 95 The moral of this example for Pakistani civil-military bureaucracy is to learn from the Chinese attitude. First, to be sure of a protective country against threats of biosecurity, CIMIC must embrace the philosophy of inclusivity - that engages the private business and the broader population. Second, public awareness and nationalism (requires some degree of re-understanding of social contract between the state and the society) must be reemphasized. Third, the legitimacy of the civil-military bureaucracy resonates with good governance, though that is domestic, however for the external front, most especially its immediate environs, it is incumbent on Pakistan's civilmilitary bureaucracy to demonstrate integrity and sense of responsibility, when it comes to threat of biosecurity.

\section{Information security and biosecurity}

Of crucial importance for the civil-military bureaucracy should not only be the technical knowledge, but information manipulation and maneuvering with regards to biosecurity. There is a nexus between information security and biosecurity. Civil-military coordination must be tailored at the fortification of the country against biosecurity threat, but they will be better accomplished, if information security is treated with the utmost seriousness, sense of responsibility and alacrity. The civil-military institutions must institute machineries for the monitoring and gathering of information, required to arrest security threat of biosecurity, well ahead of time, even before happening. The manner with which the security

\footnotetext{
${ }^{94}$ Steven Lee Myers, Keith Bradsher, Sui-Lee Wee and Chris Buckley, "Power, Patriotism and 1.4 Billion People: How China Beat the Virus and Roared Back," New York Times, February. 5, 2021, https://www.nytimes.com/2021/02/05/ world/asia/china-covideconomy.html

${ }^{95}$ Wei Tian, "How China Managed the COVID-19 Pandemic," Asian Economic Papers. 20, no 1(2021):75-101. doi: https://doi.org/10.1162/asep_a_00800
} 
Securitizing Biosecurity: The Scope for Civil-Military Coordination ...

agencies monitor and keep abreast with information that could destabilize human and state security must be replicated for biosecurity. It is high time that civil-military coordination is channelized towards a more functional and pragmatic policy - prepared for biosecurity threat before occurrence. The country needs similar resolve, policy document, and attitude demonstrated after the dastard attacks at Army Public School (APS) Peshawar. Unlike the APS tragedy, the country and the civil-military bureaucracy cannot afford to be indifferent towards biosecurity misfortune and thereafter grapples with actions to be taken. Without mincing words, information sharing is an essential prerequisite needed for an effective civil-military coordination on biosecurity. The perennial information withholding practices will be more endangering and will certainly impair the prospect of addressing the potential threats of biosecurity.

\section{Public awareness}

One of Pakistan's most functional and effective information tool is the Inter-Services Public Relations (ISPR), a media and PR wing of the Pakistan Armed Forces. In addition to this platform, the civilian government should create a public nudge (through state owned private media and, of course, the social media) meant to sensitize public towards the ferocity, intensity, and rapidity of the associated consequences of biosecurity threat. Factory owners and districts, laboratories, farmers, schools and the general public should be nudged in terms of preparedness and safety measures in the event of biosecurity threat. For instance, like Israel, it should have an alert system in the event of attack. Similarly, like Japan, it should have an alert system for natural disasters. Pakistan does not have an alert system for eventuality of biosecurity threat. As a nuclear power state, alert preparedness must be in place to prevent massive casualty in the event of nuclear mishap. While it is incontestable that the military has a commendable grip over the nuclear facility, either against theft by non-state actors or enemy intrusion, still, it is imperative to have a decentralized alert mechanism - for prompt precaution and contingency in the event of such accident. Public awareness under a serious civil-military coordination must remain perpetual as precautionary measures against the 
Securitizing Biosecurity: The Scope for Civil-Military Coordination ...

inadvertent, inappropriate, or intentional malicious or malevolent use of potentially dangerous biological agents or biotechnology, including the development, production, stockpiling, or use of biological weapons. Irrespective of the lapses, it is worth mentioning the effective nudge, created following the outbreak of the Covid-19 pandemic. Pakistan should build on the existing strength of handling the Covid-19 and its disaster management mechanism, which is decentralized. The NCOC serves as an excellent example in terms of assessment, identification, and mobilization of resources for risk and threat mitigation from biological threat, such as Covid-19. Civil-military coordination must be further enhanced and replicated to address all other areas of biosecurity. Public awareness must not be centralized, there has to be a concord and correspondence between the nature (ferocity, rapidity and intensity) of biosecurity threat and the response. The approach of civil-military coordination towards it, must be decentralized. For a large and growing population like Pakistan, centralized readiness for biosecurity threats will be appalling to logic. Such decentralized civil-military coordination will not only enhance the practicality of the objective, it will also make it more citizen oriented. Decentralization of the coordination to the grassroots is imperative, keeping in view that biosecurity transcends biosafety in the medical and research facilities, it includes food production, by extension food security, hence local farmers and food processing industries must be enlightened and sensitized to biosecurity threats.

\section{Specialized think tank:}

Pakistan is relatively replete with dozens of think tanks, whose works must be appreciated. Yet, the need for a specialized think tank for issues such as biosecurity is an undisputable exigency. Such specialized platform will particularly focus on the different aspects of biosecurity without an exemption or bifurcation of biosecurity and biosafety. Such think tank should be entrusted with the task of generating debates at policy and nonpolicy level, involving all civilian and military stakeholders and its main purpose should be the production of policy measures against (internal and external) plausible threats from biosecurity. Same think tank will coordinate some form of consultations between the civilian and military 
Securitizing Biosecurity: The Scope for Civil-Military Coordination ...

experts. The existence of such platform will bring civil-military coordination in Pakistan closer to Krasner's description of a regime - a frontier of convergence of expectations and interest. ${ }^{96}$ To legalize such a regime, a separate law on biosecurity needs to be promulgated by the parliament and the implementation taskforce will involve the think tanks and do-tanks.

\section{Conclusion}

To place the discussion in perspective, throughout this study, the paper explored the significance of biosecurity, not just in the traditional sense as defense against acts of bioterrorism, but also from a non-traditional standpoint (i.e., the role it plays in human security). The discussion has spanned from the varying definitions of biosecurity and the significant role in medicine, biosciences, governance, and defense. Even though 182 states are signatories to the BWC, it is easy to dismiss a biological attack threat. There is still benefit in improving biosecurity based on the emerging naturally occurring biological threats (like pandemic viruses) and the widely available information and research on the advances in biosciences.

Interestingly, the paper has offered a conceptual framework to understand the need for civil-military coordination in improving biosecurity. It also emphasized the role that information plays in biosecurity phases. It further emphasized the significance of considering security and governance through a biosecurity lens. Subsequently, it has highlighted methodological consideration (purposive interviews), the practical scope for civil-military coordination in Pakistan, concerning biosecurity. The findings expose the problems of governance and transparency in related sectors in Pakistan; however, to develop a comprehensive definition for the term biosecurity, interviewees see the need for cooperation across all related sectors. Since each group's priorities are different, for the time being, biosecurity may be ignored; however, its significance is not denied.

\footnotetext{
${ }^{96}$ Stephen Krasner, "Structural Causes and Regime Consequences: Regimes as Intervening Variables," International Organization 36, no 2 (1982): 185-205.
} 
Securitizing Biosecurity: The Scope for Civil-Military Coordination ...

Instead, it is considered a lesser priority. While deeming the role of information (education and research) as necessary, interviewees' different interests and priorities further confirm the gap between the government and the discipline. Premised on the divergent views amongst the experts, biosecurity is considered necessary for Pakistan's progress, but it cannot be a priority while our relations with India remain tumultuous, and the situation in Kashmir persists. Finally, this study's findings suggest that firstly, Pakistan must improve its public health care system. Issues of doctors' security and addressing the shortage of doctors, by improving funding and salaries so that they may feel secure. Additionally, the role of information generation and access needs to be taken more seriously. For greater chances of civil-military coordination in this regard, all sectors need to align their goals, the onus of this alignment will be on the state while the academia and the discipline will follow 